\title{
A study and Description of the Femtocells Wireless Communication Networks
}

*Fathi Alwafie ${ }^{\text {a }}$, Ali Ukasha ${ }^{\text {a }}$, Nabeil A. Abujnah ${ }^{\mathrm{b}}$

${ }^{a}$ Department of Electrical and Electronic Engineering, Faculty of Science Engineering and Technology, University of Sabha-Libya. ${ }^{b}$ Department of Electrical and Electronic Engineering, Faculty of Engineering, University of Azzaytuna-Libya

\section{Keywords:}

Femtocells

Wireless communication

Macrocells

\begin{abstract}
A B S T R A C T
In this paper the femtocell base station called as Femtocell Access Point (FAP) was descriped and studied. The femtocell (FAP) is fully user deployed and hence reduces the infrastructure, maintenance and operational cost of the operator while at the same time providing good Quality of Service (QoS) to the end user and high network capacity gains. The surest way to increase the system capacity and data rates can be achieved efficiently in a wireless system by getting the transmitter and receiver closer to each other. In a network with nomadic users, this inevitably involves improving more infrastructure, typically in the form of microcells, hotspots, distributed antennas, or relays. Femtocells deployed in the macrocell significantly improve the indoor coverage and provide better user experience. In this paper the four indoor propagation path loss models with simulated data for different scenarios at $2 \mathrm{GHz}$ are presented In additions the Simulation were carried out in two different scenarios LOS and NLOS for max $50 \mathrm{~m}$ femtocell and max $100 \mathrm{~m}$ macrocell network. The simulation results was implemented using Matlab code software.
\end{abstract}

$$
\text { دراسـة ووصف شبكات اتصـالات خلايا الفيمتو اللاسلكية }
$$$$
\text { 1قسم الهندسة الكهربائية والالكترونية، كلية العلوم الهندسية والتقنية، جامعة سبها، ليبيا }
$$

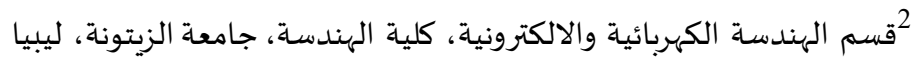

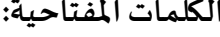
خلايا الفيمتو

اتصالات لاسلكية الخلايا الكبيرة

في هذه الورقة تم توصيف ودراسة نقطة الوصول لخلية الفيمتو. تعيين خلية فيمتو تتم بالكامل من قبل المشغل وبالتالى يقلل من البنية التحتية والصيانة والتكلفة التشغيلية للمشغل وايضاً في نفس الوقت يوفر جودة الخدمة الجيدة للمستخدم الههائي وكسب عالي فى سعة الشبكة. يمكن تحقيق أفضل طريقة لزيادة سعة النظام ومعدلات

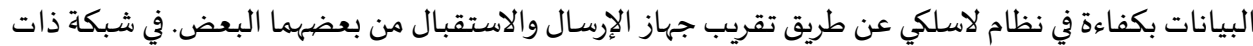

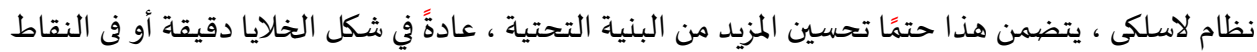

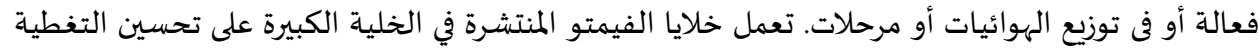

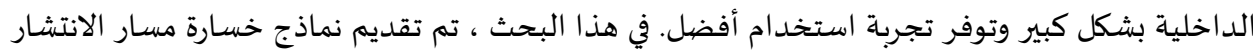

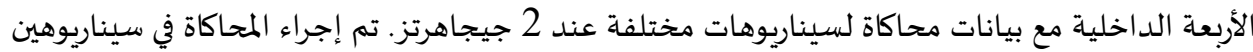
مختلفين LOS و NLOS لشبكة خلية فيمتو بحد أقصى 50 م و 100 م كحد أقصى. تم تنفيذ نتائج المحاكاة باستخد ام برنامج الماتلاب.

\footnotetext{
*Corresponding author:
}

E-mail addresses: fat.alwafie@ sebhau.edu.ly, (A. Ukasha) ali.ukasha@ sebhau.edu.ly,(N. Abjnah)n.abujnah39@gmail.com Article History : Received 26 April 2021 - Received in revised form 09 June 2021 - Accepted 15 July 2021 


\section{Introduction}

In cellular networks, it is estimated that $2 / 3$ of calls and over $90 \%$ of data services occur indoors. Hence, it is extremely important for cellular operators to provide good indoor coverage for not only voice but also video and high speed data services, which are becoming increasingly important. However, some surveys show that $45 \%$ of households and $30 \%$ of businesses experience poor indoor coverage problem [1]. Good indoor coverage and service quality will generate more revenues for operators, enhance subscriber loyalty and reduce churn. On the other hand, poor indoor coverage will do exactly the opposite. Hence, how to provide good indoor coverage, in particular, for high speed data services, is a big challenge for operators.

The indoor solutions such as DAS (Distributed Antenna Systems) and picocells become an attractive and viable business proposition in hotspots such as large business centres, office buildings and shopping malls. These indoor systems are deployed by operators. The indoor solutions will improve in-building coverage, offload traffic from outdoor macrocells, enhance service quality and facilitate high data rate services due to the improved performance of radio links. With indoor solutions, in UMTS, the orthogonality can be improved, which will result in high throughput [2]. In HSPA/LTE or WiMAX, the better channel conditions will enable high modulation and coding scheme to be used and thus deliver richer services that further drive demand. Even though the above mentioned indoor solutions are more cost effective than using outdoor macrocells to provide indoor coverage for voice and high speed data services, such solutions are still too expensive to be used in some scenarios such as SOHO (Small Office and Home Office) and home users (for personal communications and entertaining, etc.). The scale of SOHO and home use normally does not represent a viable business proposition for operators. Recently, the development of femtocells provides a good opportunity for low cost indoor solutions for such scenarios. Unlike picocells, femtocells are deployed by users [3], [4]. Femtocells, also known as 'home base station', are cellular network access points that connect standard mobile devices to a mobile operator's network using residential DSL, cable broadband connections, optical fibres or wireless last-mile technologies.

The concept of 'home base station' was first studied by Bell Labs of Alcatel-Lucent in 1999. In 2002, Motorola announced the first 3Gbased home base station product. However, it was not until 2005 that the 'home base station' concept started to gain a wider acceptance. In 2006, 'femtocell' as a term was coined. In February 2007, a number of companies demonstrated femtocells at the 3GSM World Congress (Barcelona), with operators announcing trials. In July 2007, the Femto Forum was founded to promote femtocell standardization and deployment worldwide [2]. As of December 2008, the forum includes over 100 telecom hardware and software vendors, mobile operators, content providers and start-ups. In 2008. Home NodeB (HNB) and Home eNodeB (HeNB) were first introduced in 3rd Generation Partnership Project (3GPP) Release 8 , signalling that it had become a mainstream wireless access technology [5]

\subsection{Macrocell \& Femtocell Integration Scenario Networks}

To improve coverage and capacity, it has been widely recognized that the focus in future should be on increasing spatial reuse and link capacity by embracing the concept of small cells, that was first introduced nearly three decades ago [6]. The idea is to scale down the size of cell that leads to higher capacity gains as a result of more efficient frequency reuse with high spatial density[6]. As such, this discussion naturally leads to the notion of Networks indicated in fig 1. which basically refers to a tiered network architecture integration using a combination of microcells, distributed antennas, relays, operator deployed picocells or consumer deployed femtocells underlying the top layer macrocell network all working together, in general, in the same system bandwidth to provide the best coverage and capacity possible. Thousands of femtocells may co-exist in a coverage area of a

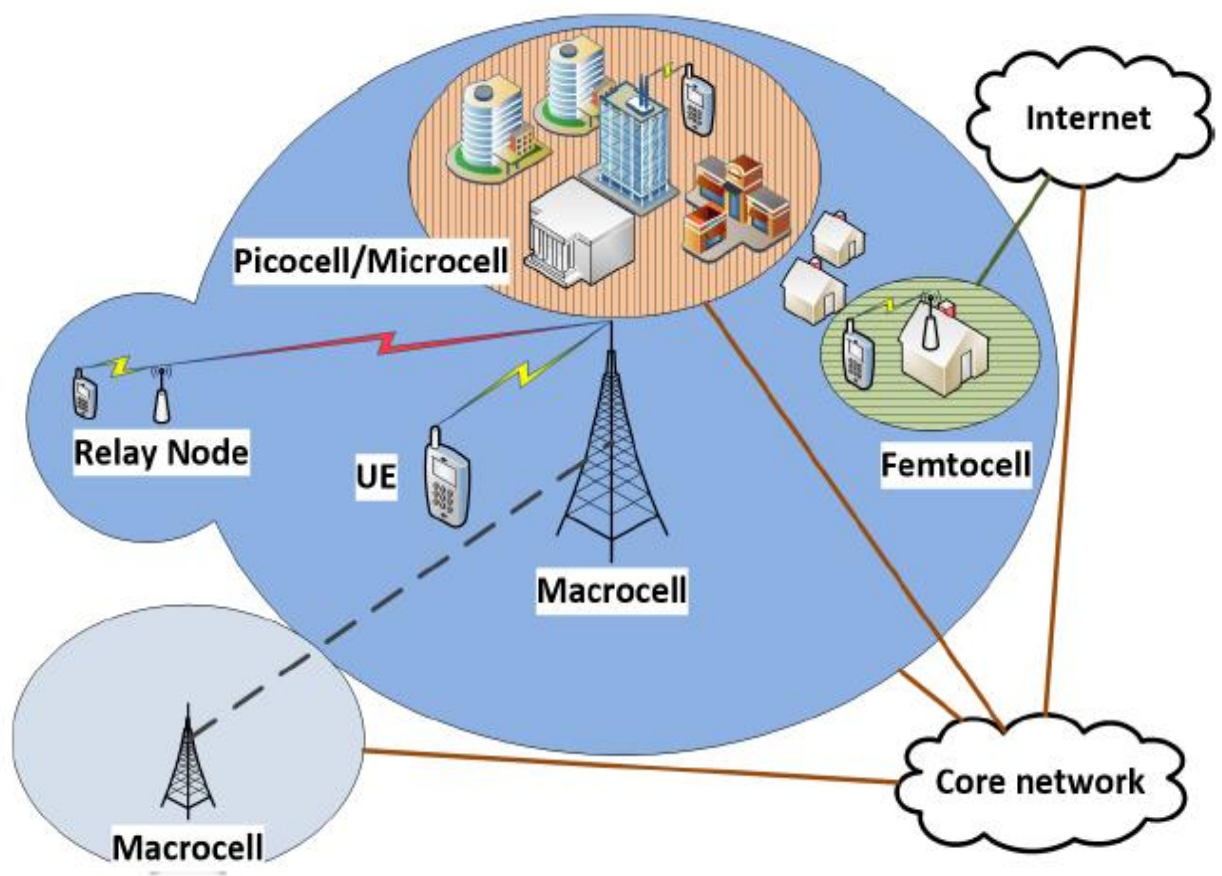

Fig. 1 Macrocell and femtocell senario networks 


\subsection{Femtocell Technologies}

The technologies behind femtocell are cellular technologies. As the key driver of femtocell is the demand for higher and higher data rates indoors, UMTS (Universal Mobile Telecommunication System), HSPA(High Speed Packet Access) and FAPs (Femtocell Access Point) are the current main focus. However, FAPs can also be based on GSM/GPRS/EDGE. 2G/3G based femtocells have been developed by various vendors. Unlike picocells, FAPs are selfdeployed by users rather than operators. They should be regarded as consumer electronics. In order to generate minimum interference to outdoor macrocells and neighboring femtocells, a FAP must be able to configure itself automatically as shown in fig 2 .

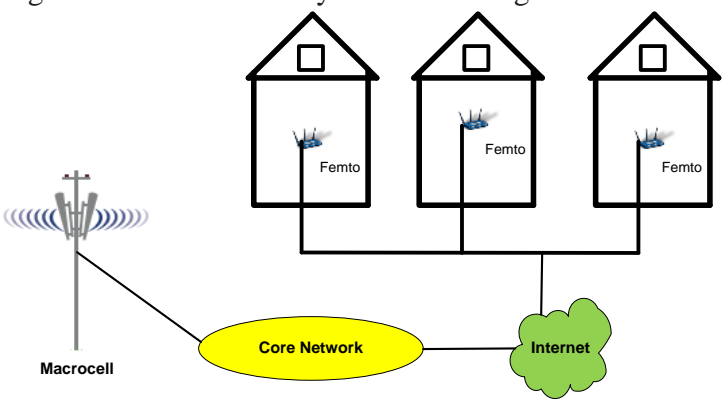

Fig 2: Typical femtocell topolgy

According to their capacity, FAP can be classified into two categories, namely home FAP, which can support 3-5 simultaneous users, and enterprise FAP, which can support 8-16 users. The key drive of FAP is to provide high data rate services for the residential sector. There is a low probability that all the subscribers will simultaneously use the femtocell, which is why home femtocells supporting more than five simultaneous users would be too useless compared with the real demand. In addition, this is also restricted by the bandwidth limitation of the uplink ADSL. According to the cellular technologies used, FAP can be classified into UMTS FAP, GSM FAP, WiMAX FAP, and so on. There is a trend to combine different air interfaces into one FAP. The femtocells are coming very important for the following reasons:

- It can provide indoor coverage for places where macrocells cannot.

- It can offload traffic from the macrocell layer and improve macrocell capacity (in the case of using macrocells to provide indoor coverage, more power from the base station will be needed to compensate for high penetration loss, resulting in a decrease in macrocell capacity).

- Femtocell provides an ideal solution for FMC (Fixed Mobile Convergence).

- Femtocell plays an important role in mobile broadband and ubiquitous communications.

- Femtocell represents a major paradigm shift. Users will pay to install femtocells. Hence, the first phase of the rollout of high data rate networks such as LTE can start from indoor where high data rates are needed most. As future terminals will support

The first application of femtocells is phone calls, which will be free or at a low price. Moreover, thanks to femtocells, some new applications can be proposed by the operators.

Because the indoor coverage will be maximum, some new data intensive services will be experienced by the customers. As described in [1], [2], the new services can be divided into two kinds of application: Femtozone Services and Connected Home Services.

\section{$>$ Femtozone Service}

These services are web/voice services that are activated when the phone comes to the range of the FAP. Some examples include:

- Receive an SMS to indicate when someone enters or leaves the home.

- A virtual number to reach all the people currently in the home.

\section{$>$ Connected Home Services}

In these kinds of service, the phone accesses the LAN via the femtocell, in order to control a range of networked services, for example:

- upload some musics from the mobile phone to the PC,

- $\quad$ use the mobile phone to control other devices (TV, HiFi).

\subsection{Improvement of Indoor Coverage}

Improving indoor radio coverage has recently become more and more important. This is the reason why different solutions have been proposed. In the past, indoor coverage was only provided by an outdoor antenna. In this approach, the only way to increase indoor coverage was to increase the power or to add more cells. This led to the creation of more small outdoor cells (microcells) providing more capacity for the network. Unfortunately, this approach is expensive for operators because they have to install more sites, which dramatically increases the maintenance costs. Moreover, this solution also creates more problems concerning interference, as more cells will overlap each other. Finally, improving indoor radio coverage by adding outdoor cells is not optimal because it does not directly optimize indoor coverage and thus the efficiency of such a method is not optimal. To overcome the limitation of outdoor cells, different approaches have been proposed in order to increase the indoor signal directly [2].

The solution is to deploy small base stations directly inside the buildings as represented in fig 3. Two main approaches have thus been proposed: the picocells and the femtocells [2].

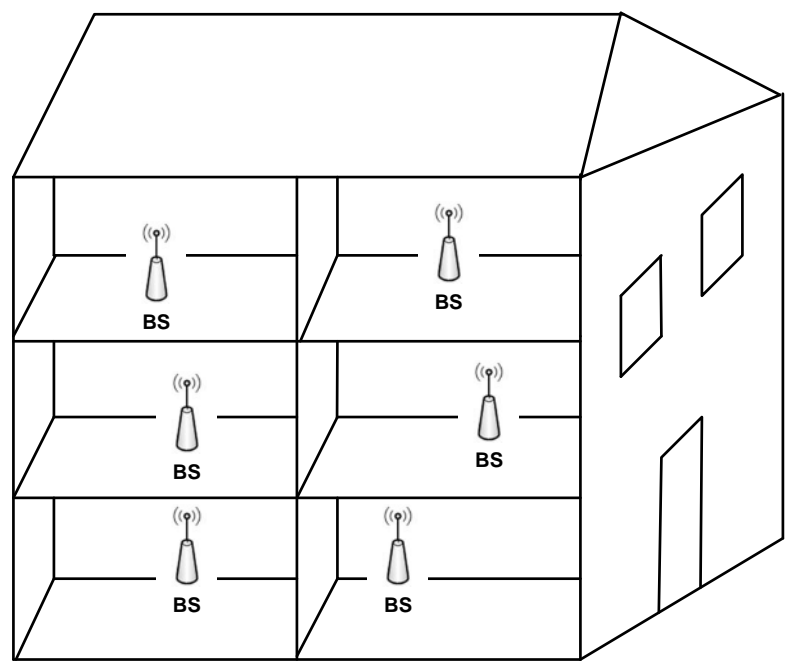

Fig 3: Indoor base station radio coverage of a three-floor building

The picocell is connected to the core network via standard in-building wiring, fibre optic or Ethernet connection. Usually an omnidirectionnal antenna is integrated into the picocell [3]. The main advantage of picocells is that they are cheaper than standard base stations, and the installation cost is also lower. They effectively increase indoor coverage because they are installed indoors. The coverage area of the cells is small compared with outdoor base stations, because the radiated power is lower, and also because of the numerous reflections and diffractions due to the walls and other obstacles inside the building. Thus, covering the inside of a building requires the use of many picocells compared with outdoor cells. This allows the operator to have more cells, and thus increase the capacity of the network inside the building. That is why picocells are deployed in indoor areas containing a high density of users. Moreover, by installing a picocell inside a building, the operator can have more capacity in the outdoor network because the outdoor cells that are used to cover the building become available just to outdoor users.

To extend the idea of picocells to home networks only, with an approach more similar to WiFi access points, femtocell base stations have been proposed. The femtocell is a simplified picocell directly installed by the customer in their home. It combines, in the same device, all the functionalities of a picocell and a BSC. Thus, instead of being connected to the operator's BSC (like a picocell), the femtocell is connected directly to the Internet as represented in fig 2 with femtocells, all the communications go to the operator's network through the Internet, and there is no need for BSC/MSC infrastructure. Femtocells, because they typically cover a smaller area and have fewer users than picocells, and because they have to be cheap, are limited in output power and capacity (between 10 and 20 $\mathrm{dBm}$, between four and six users). This ensures a smooth 
communication for the user and a maximal coverage is obtained inside the home [8].

\subsection{Interference Analysis in Femtocell Netowrks}

Frequency planning in femtocell networks is very crucial. Without precise spectrum allocation for the femtocell network could suffer from severe interference problems. In heterogeneous networks, cochannel deployment of multiple layers of network introduces interference. Generally, there are two types of interference associated with the co-channel deployment of heterogeneous networks comprising macrocells and femtocells, which are cross-layer interference and co-layer interference. Depending on whether a macrocell layer exists or not, or whether the FAP are deployed singularly or grouped as a network, the various cases of possible different types of interference scenarios in two-layer networks are explained in fig 4.

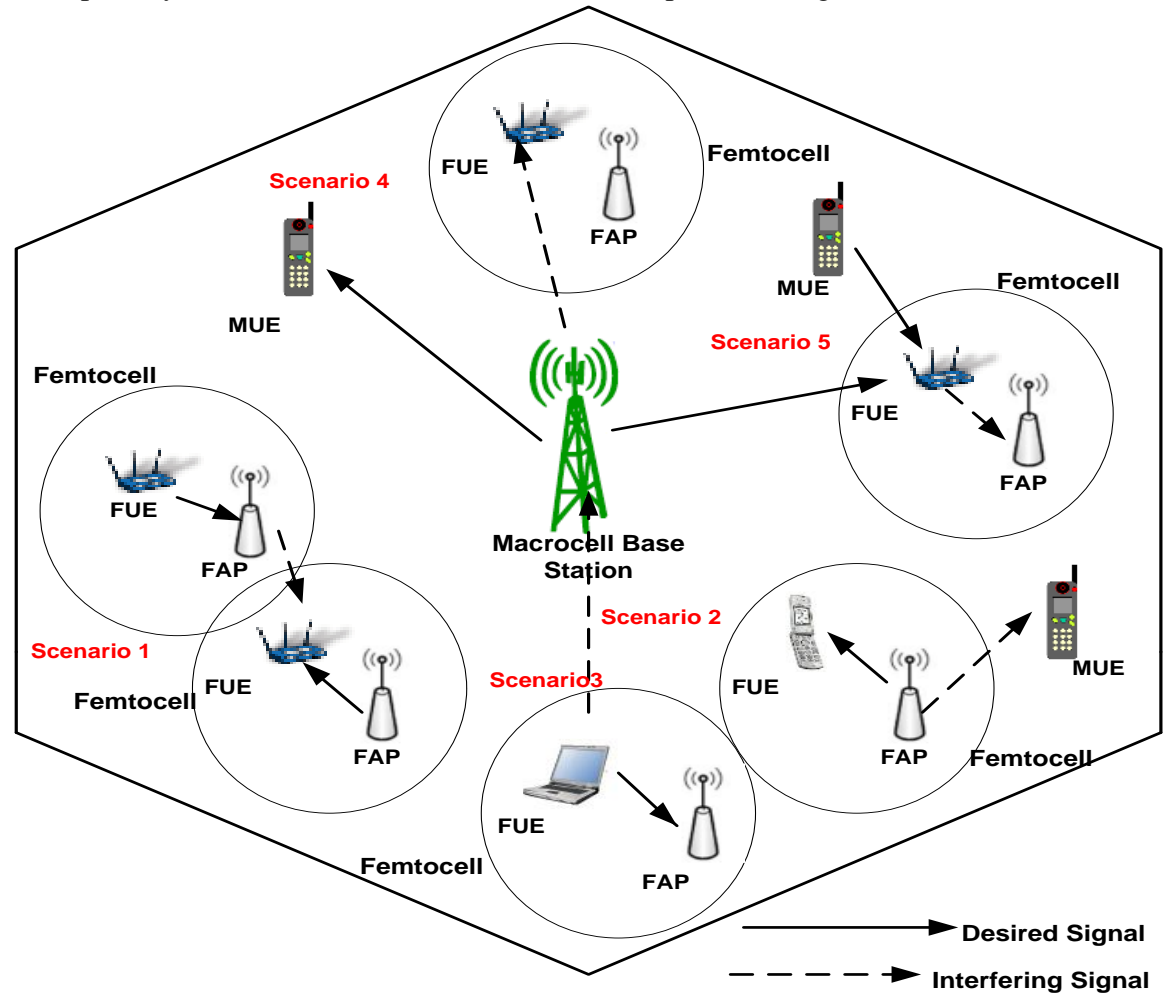

Fig 4: Interference scenarios in macrodell and fetocellnetworks.

In scenario 1, downlink co-layer interference occurs between an FAP and a near FUE, while FAP is communicating with its associated FUE. In scenario 2, downlink cross-layer interference occurs between an FAP and a nearby MUE, while the FAP is communicating with its attached FUE. Downlink is the channel from a base station to a user equipment. In scenario 3, uplink cross-layer interference occurs between an FUE and a neighbouring macrocell base station (MBS), while the FUE is communicating with its serving FAP. Uplink is the channel from a user equipment to a base station. In scenario 4, downlink cross-layer interference occurs between an MBS and a nearby FUE, while the MBS is communicating with its attached MUE. In scenario 5, uplink co-layer interference occurs between an FUE and neighbouring FAP, while the MBS is communicating with its serving FUE [2], [11], [12].

\subsection{Mathematical Model of Femtocells Consideration}

The number of femtocells needed to cover certain areas may or may not provide adequate coverage depending on the macro receive signal strength , and also the optimum number of femtocells needed to cover a given area cannot be determined a priori as it is dependent on the location of macrocells. The number of femtocells that are required for a given coverage is decided by maximum tolerable path loss to the serving cell. Depending on the type of deployment scenarios the coverage area for a given path loss is different. Given the area of deployment scenarios and femtocell coverage area the optimum numbers of femtocells required are given as shown in equation:

$$
\text { Number of femtocells }=\frac{\text { Area }}{\text { Femto coverage area }}
$$

\subsubsection{Path Loss Indoor Propagation Model}

During the signal propagation between the transmitter and the receiver, the signal strength degrades due to the interaction with the surrounding environment. Different types of propagation models were proposed.

\subsubsection{Multi Wall Multi Floor Model (MWMF)}

For the femtocells category in agiven the condo building, the path loss can be calculated by one of indoor propagation model [11]. The path loss is expressed as:

$$
L_{m w f}=L_{o}+10 n \log (d)+\sum_{i=1}^{I} \sum_{s=1}^{S_{w i}} L_{w i s}+\sum_{j=1}^{J} \sum_{s=1}^{S_{f j}} L_{f j s}
$$

Where $\mathrm{L}_{\text {wis }}$ and $\mathrm{L}_{\text {fis }}$ are the loss of $\mathrm{S}^{\text {th }}$ wall and floor that has been traversed $(\mathrm{dB})$ and $\mathrm{S}_{\mathrm{wi}}$ and $\mathrm{S}_{\mathrm{fi}}$ are number of traversed walls and floors. $I$ is the number of walls, and $J$ is the number of floors, $n$ is the power decay index, and $\mathrm{d}$ is the distance.

\subsubsection{IEEE 802.11n Model}

This model defined a breakpoint (Bp) distance where the path loss before this Bp follows the free space loss LFS (slope of 2) and after the Bp the slope is increased up to 3.5 [ 9 ], and can be calculated by following equation:

$$
\mathrm{PL}=\mathrm{L}_{\mathrm{FSL}}\left(\mathrm{B}_{\mathrm{P}}\right)+10 \mathrm{n} \log \left(\frac{\mathrm{d}}{\mathrm{d}_{\mathrm{BP}_{\mathrm{P}}}}\right)
$$

where; $d$ represent the distance, $d_{B P}$ breakpoint distance, and LFSL free space loss.

\subsubsection{ITU-R M.2135}

The model is proposed for LOS and NLOS respectively :

$$
\begin{aligned}
& \text { PL }(\text { LOS })=16.9 \log (d)+32.8+20 \log \left(f_{C}\right) \\
& \text { PL }(N L O S)=43.3 \log (d)+11.5+20 \log \left(f_{C}\right)
\end{aligned}
$$

Where $f_{c}$ the frequency in GHz.

\subsection{Simulation Results and Discussion}

Based on the mathematical analysis given in Section 1.5, a simulation framework that applies for the pathloss for femtocells and macrocells are estimated. The simulation carried out in MATLAB is based on the simulation parameters are listed in Table 1. 
Table 1 : Parameters of Simulation scenario

\begin{tabular}{cc} 
Parameter Description & value \\
\hline Frequency & $2 \mathrm{GHz}$ \\
Power index decay & 1.9 \\
Loss of wall & 2 \\
Loss of floor & 5 \\
Max number of walls I & 10 \\
Max number of floors j & 10 \\
Break point distance & 3.5 \\
Max femtocell radius & $50 \mathrm{~m}$ \\
Max macrocell radius & $100 \mathrm{~m}$ \\
\hline
\end{tabular}

This module implements the mathematical models corresponding to all possible cross-layer and co-layer with different propagation model, for the Femtocell and macrocell environments. From fig 5, with one wall and one floor, the relationship between path loss and distance can be establish and the impact of distance on coverage can clearly be seen. When the distance increased, the path loss increases. fig 6 show how the path loss increases as the number of walls and floors increases to 5 and 3 respectively. From the fig 5 , and fig 6 , we indicate the path loss for MWMF is low as compared to others considering 1 number of wall and 1 number of floor.

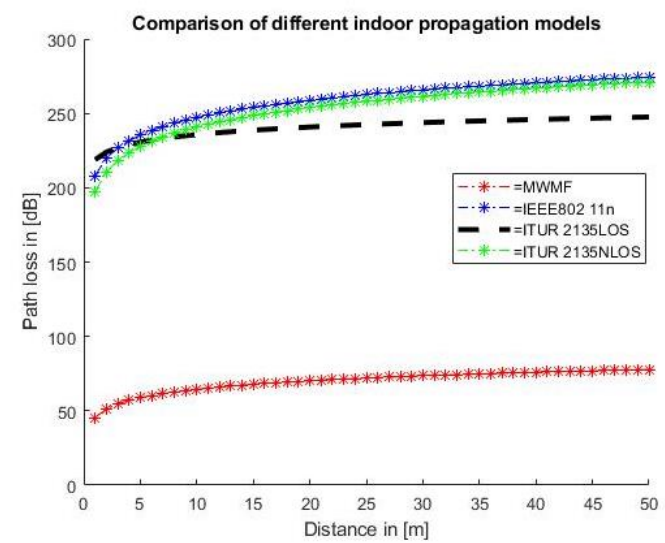

Fig 5 : Pathloss for different indoor propagation model with 1 wall and 1 floor

The next fig 7 and fig 8, the path loss of femtocell is lower than that of macrocell cellular network. As the number of walls and floors are increasing, the losses are increasing as well. In addition the path loss depends on LOS and NLOS of transmitter and receiver. The path loss of LOS is lower than that of NLOS as well as it is indicated in these graphs. It is clearly visible that increasing the number of walls and floors decreases the path loss. The loss corresponds to walls and floors are different.

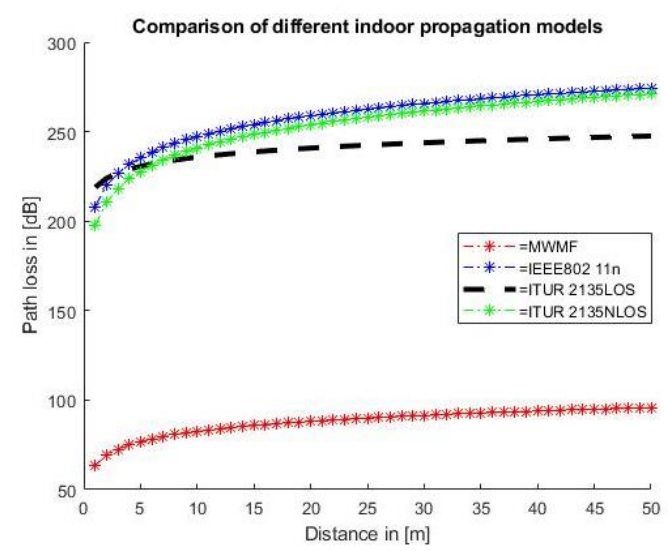

Fig 6 : Pathloss for different indoor propagation model with 5 walls and 3 floors

This depends on materials that are used for such building like concrete, wood, steel, bricks and etc.

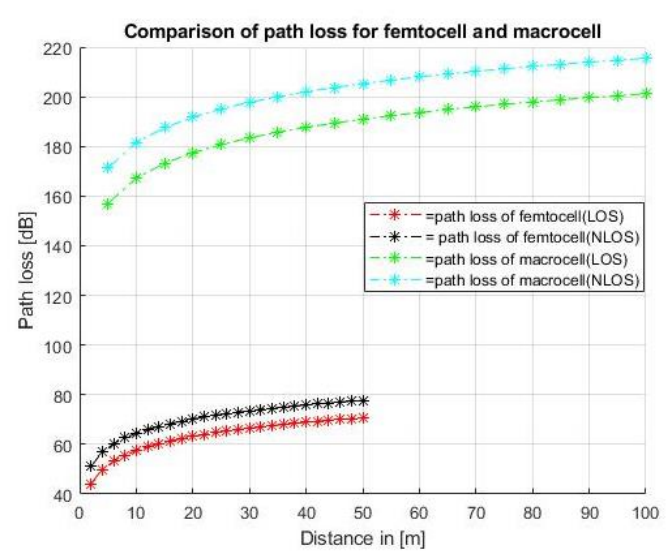

Fig 7 : Path loss of femtocell and macrocell with 1 wall and 1 floor

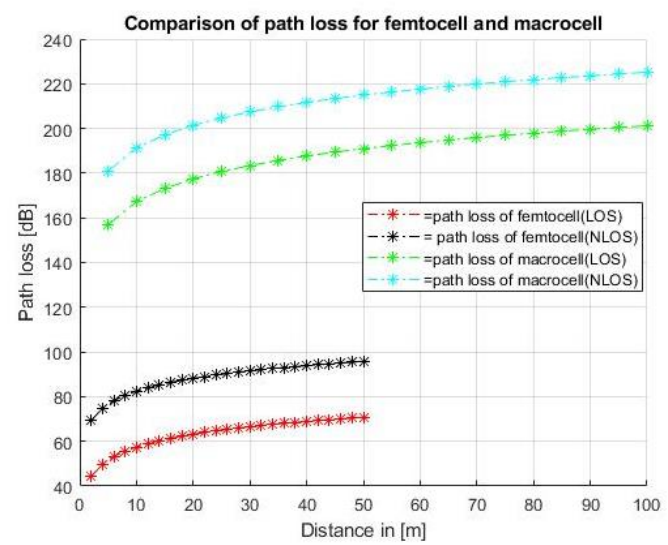

Fig 8 : Path loss of femtocell and macrocell with 5 walls and 3 floors

\section{Conclusion}

Integration of femtocell networks with macrocell networks, as well as with other non wireless networks, is essential for the successful deployment of the femtocell technology. Femtocells are considered to be the solution to meet the future needs for high data rates and capacity in the wireless cellular networks. This paper has identified the key benefits of femtocells, and provides a basic overview of femtocells starting from their background and history. It provides an insight into the potential research areas of femtocells that can be explored.

In this paper the four indoor propagation path loss models with simulated data for different scenarios at $2 \mathrm{GHz}$ are presented. The MWMF model show the best result compared by other models. In additions the Simulation were carried out in two different scenarios LOS and NLOS for max $50 \mathrm{~m}$ femtocell and max $100 \mathrm{~m}$ macrocell network. It is clear that the LOS scenario show less loss compared with NLOS scenario. The results show us to takes into account the inter-action of penetrated walls and floors, the locations of FAP, parameters of construction of networks.

\section{References}

[1]- J. Cullen, 'Radioframe presentation,' in Femtocell Europe 2008, London, UK, June 2008.

[2]- Jie. Zhang, and G. Da La Roche, FemtoCells Technologies and Deployment, . JohnWiley \& Sons, Ltd, $1^{\text {st } 2010 .}$

[3]- M. Smith, A. Bush, P. Gwynn, and S. Amos, 'Microcell and picocell base station internal antennas,' in IEEE Wireless Communications and Networking Conference, WCNC, vol. 2, Sept 1999, pp. 708-711.

[4]- E. Kudoh, A. Shibuya, T. Ogawa, D. Uchida, M. Nakatsugawa, H. Suda, and S. Kubota, 'Picocell network for local positioning and information system,' in 26th Annual Confjerence of the IEEE Industrial Electronics Society, vol. 2, Oct 2000, pp. 11651170 .

[5]- C. Johnson and J. Khalab, 'Load based radio resource management for umts picocells,' in 4th International Conference on 3G Mobile Communication Technologies, June 2003, pp. 88-92. 
[6]- Y.-U. Chung and D.-H. Cho, 'Performance analysis of handoff algorithm in fiber-optic microcell/picocell radio system,' in IEEE 51st Vehicular Technology Conference Proceedings, VTC 2000-Spring, vol. 3, May 2000, pp. 2408-2412.

[7]- D. Molkdar, 'Simulation results of a typical gsm picocellular system,' in 52nd IEEE Vehicular Technology Conference, VTC-Fall, vol. 4, Sept 2000, pp. 1590-1596.

[8]- V. Chandrasekhar and J. G. Andrews, 'Femtocell networks: A survey,' IEEE Communication Magazine, vol. 46, no. 9, pp. 5967, September 2008.

[9]- Alhareth. M. Zyoud, Mohamed. H. Habaebi, Jalel. C, and Md. Rafiqul Islam, ' Investigation of three dimensional empirical indoor path loss models for femtocell networks,' In 5th International Conference on Mechatronics, vol 53, (ICOM'13), 2013.

[10]- Marek Sedlacek, "Identification of femtocells in mobile networks," docrorat thesis, April 2017, Czech Technical University in Prague.

[11]- Matthias Lott, and Ingo Forkel, ‘ A Multi-Wall-and-Floor Model for Indoor Radio Propagation, ' IEEE VTS 53rd Vehicular Technology Conference, Rhodes-Greece, May 2001.

[12]- Chandrasekhar. V, Andrews, J. G, and Gatherer. A, "Femtocell networks: a survey," IEEE Communications magazine, vol 46(9), pp 59-67. Sep 2008. 